Na silicate and $\mathrm{NaPO}_{3}$ glasses. The $\mathrm{Na}^{+}$diffusion in $\mathrm{SiO}_{2}$ glass is, therefore, considered as a limiting case where $\mathrm{Na}^{+}$ions have the highest capability for random (uncorrelated) motion.

Acknowledgments: The writers thank P. C. Schultz and P. P. Bihuniak of Corning Glass Works and J. H. Simmons of Catholic University for providing samples for this study.

\section{References}

${ }^{1}$ C. Lim and D. E. Day, "Sodium Diffusion in Glass: I," J. Am. Ceram. Soc.. 60 [5-6] 198-203 (1977)

2C. Lim and D. E. Day, "Sodium Diffusion in Glass: II." ibid., [11-12] 473-77. ${ }^{3}$ C. Lim and D. E. Day, "Sodium Diffusion in Glass: III," ibid., 61 [3-4] 99-102 (1978).

${ }^{4}$ Y. Haven and J. M. Stcvels; pp, 343-47 in IVth International Congress on Glass,

Paris, 1956. Imprimeric Chaix, Paris, 1957.

Y. Haven and B. Verkerk, "Diffusion and Electrical Conductivity of Sodium Ions in Sodium Silicate Glasses," Phys. Chem. Glasses. 6 [2] 38-45 (1965).

"L. W. Barr, J. N. Mundy, and A. H. Rowe; pp. 243-50 in Amorphous Materials. Edited by R. W. Douglas and Bryan Ellis. Wiley-Interscience, New York, 1972.

${ }^{7}$ G. H. Frischat, Ionic Diffusion in Oxide Glasses (Diffusion Monograph Series,

No. 3/4). Trans Tech Publications, Bay Village, Ohto, 1975; $182 \mathrm{pp}$

A. D. Le Claire; pp. 261-330 in Physical Chemistry, An Advanced Treatise, Vol.

10. Edited by W. Jost. Academic Press. New York, 1970.
" N. L. Peterson; pp. 115-70 in Diffusion in Solids: Recent Developments. Edited by A. S. Nowick and J. J. Burton. Academic Press, New York, 1975.

"P. G. Shewmon, Diffusion in Solids; pp. 7-11. McGraw-Hill, New York, 1963

"L. W. Barr and A. D. Le Claire, "Correlation Effects in Diffusion," Proc, Br. L. W. Barr and A. D. Le Claire, "Cor
Ceram. Soc, 1964, No. 1. pp. 109-28.

${ }^{12}$ J. H. Simmons, "Molecular Stuffing Process for Making High Silica Glasses with Controlled Properties"; unpublished work.

${ }_{13}$ P. B. Macedo, C. T. Moynihan, and R. Bose. "Role of Ionic Diffusion in Polarization in Vitreous Ionic Conductors," Phys. Chem. Glasses, 13 [6] 171-79 (1972).

${ }^{14}$ G. H. Frischat "Sodium Diffusion in Various Vitreous Silicas," Glastech Ber. 43 [12] 482-88 (1970).

R.H. Doremus, "Electrical Conductivity and Electrolysis of Alkali Ions in Silica Glass." Phy.s. Chem. Glasses. 10 [1] 28-33 (1969).

${ }^{16}$ R. H. Doremus, "Ionic Transport in Amorphous Oxides," I. Electrochem. Sou , 115 [2] $181-86$ (1968).

${ }^{17}$ H. M. Garfinkel, "Ion Exchange Properties of Borosilicate Glass Membranes in Molten Salts." Phys. Cham. Glasse's. 11 [5] 15]-58 (1970)

${ }^{18} \mathrm{R}$. Terai and R. Hayami. "Ionic Diffusion in Glasses," $j$. Non-Cryst Solids, 18 [2] 217-64 (1975).

${ }_{1 "}$ R. H. Doremus, "Exchange and Diffusion of Ions in Glass," J. Phys. Chem., 68 [8] 2212-18 (1964).

${ }^{20} \mathrm{~F}$. Nicolas. F. Beniere, and M. Chemla, "Isotepe Effect of Diffusion of ${ }^{22} \mathrm{Na}^{+}$${ }^{24} \mathrm{Na}^{+}$in $\mathrm{NaCl}, \mathrm{KCl}$, and $\mathrm{KBr}$ Single Crystals," J, Phys. Chom. Solids, 35 [1] I5-23 (1974).

21 W. M. Jones, "Permeability and Solubility of $\mathrm{He}^{\text {" }}$ and $\mathrm{He}^{4}$ in Vitreous Silica" Am. Chem. So.. 75, 3093-96 (1953).

${ }_{22}$ R. C. Frank, D. E. Swets, and R. W. Lee, "Diffusion of Neon Isotopes in Fused Quartz," J. Chem. Phys. 35 [4] 1451-59 (1961).

\title{
Solid-Liquid Equilibria in the System $\mathrm{Si}_{3} \mathrm{~N}_{\mathbf{4}}-\mathrm{AIN}-\mathrm{SiO}_{2}-\mathrm{Al}_{2} \mathrm{O}_{3}$
}

\author{
I. K. NAIK, ${ }^{\star * *}$ L. J. GAUCKLER, ${ }^{*}$ and T. Y. TIEN* \\ Department of Materials and Metallurgical Engineering, The University of Michigan, Ann Arbor, Michigan 48109
}

\begin{abstract}
Solid-liquid equilibria at $1750^{\circ} \mathrm{C}$ and subsolidus phase relations in the system $\mathrm{Si}_{3} \mathrm{~N}_{4}-\mathrm{AlN}-\mathrm{SiO}_{2}-\mathrm{Al}_{2} \mathrm{O}_{3}$ were determined for the composition region bounded by the $\beta-\mathrm{Si}_{3} \mathrm{~N}_{4}$ solid solution line and silica-alumina join. $X$-ray diffraction and optical microscopy were used to determine the phases present in specimens cooled rapidly after equilibration. The extent of a single liquidphase region and the tie lines for the $\beta$-solid solution + liquid field at $1750^{\circ} \mathrm{C}$ were established from quantitative $X$-ray diffractometry and lattice parameter measurements of $\beta$-solid solutions in equilibrium with liquid. The results were corroborated by optical microscopy and melting behavior observations. A new composition, $\mathrm{Si}_{12} \mathrm{Al}_{18} \mathrm{O}_{39} \mathrm{~N}_{8}$, is suggested for the $x_{1}$ phase. The lowest melting temperature in the system is $\approx 1480^{\circ} \mathrm{C}$ and the corresponding composition is $10 \mathrm{eq} \% \mathrm{Al}$ 90 eq\% 0 .
\end{abstract}

\section{Introduction}

$\mathbf{C}$ ERAMIC materials based on the system $\mathrm{Si}, \mathrm{Al} / \mathrm{N}, \mathrm{O}$ are currently being considered as one of the promising candidates for structural application in an energy-efficient gas turbine. Boskovic et al. ${ }^{1}$ showed that $\mathrm{Si}_{3} \mathrm{~N}_{4}$-based ceramics can be made by pressureless sintering. Since $\mathrm{Si}_{3} \mathrm{~N}_{4}$-based materials have significant covalent character in their bond scheme, sintering to high density via solid state diffusion is not possible. Therefore, the alternative possibility of sintering in the presence of a liquid must be considered. For a liquid-phase sintering process, it is necessary to understand the solid-liquid equilibria in this system. Since such information is scarce in the literature, a study of these equilibria was undertaken.

Presented at the Fall Meeting of the Basic Science and Nuclear Divisions, The American Ceramic Society, Hyannis, Mass., September 26, 1977 (Paper No. 13$\mathrm{BN}-77 \mathrm{~F})$.

Received September 2, 1977; revised copy received January 23, 1978.

Supported by the U.S. Air Force Office of Scientific Research under Grant No. AFOSR-76-3078.

"Member, the American Ceramic Society.

*Now with the AiResearch Casting Co., Torrance, California 90509.
The early work on phase relations in the system $\mathrm{Si}, \mathrm{Al} / \mathrm{N}, \mathrm{O}$ concerned the formation and nature of the $\beta-\mathrm{Si}_{3} \mathrm{~N}_{4}$-based solid solution $(\beta-s s)$ and other solid phases in the system. ${ }^{2-4}$ The first detailed study of subsolidus equilibria was reported by Gauckler et al. ${ }^{5}$ who found that, at $1760^{\circ} \mathrm{C}$, adjacent the $\mathrm{SiO}_{2}$-rich side of the $\beta$-ss phase, a 2 -phase region (liquid $+\beta$-ss) existed. However, the solid-liquid equilibria were not studied in detail. Land et al. ${ }^{6}$ reported that liquid in this system was confined to the region close to the $\mathrm{SiO}_{2}$ corner and that there was no region where $\beta$-ss and liquid coexisted at $1800^{\circ} \mathrm{C}$ in their product or quasi-equilibrium diagram. They also reported that the $x_{1}$ phase does not melt at $<1800^{\circ} \mathrm{C}$. Layden ${ }^{7}$ proposed a tentative liquid-phase field using differential thermal analysis (DTA) and microstructure observations. The liquid field extends from the $\mathrm{SiO}_{2}$ corner and includes the $x_{1}$ composition at $1750^{\circ} \mathrm{C}$. The $x_{1}$ phase reportedly melts at $\approx 1720^{\circ} \mathrm{C}$. A large $\beta$-ss + liquid field is also indicated at $1750^{\circ} \mathrm{C}$. Layden had difficulty in getting reasonable signal strengths during melting due to foaming of the liquid at the high temperatures involved. Therefore, an alternative method of quantitative phase analysis by $\mathrm{X}$-ray powder diffractometry on a series of well-selected specimens should prove to be a more reliable method of studying solid-liquid equilibria in this system.

\section{Experimental Procedure and Observations}

The starting materials used were aluminum nitride, ${ }^{\dagger}$ silicon nitride, ${ }^{*}$ alumina, $\$$ and silica." The oxygen contents of the nitrides were considered in making up the compositions. Mixtures of different overall compositions in the region between the $\beta$-ss line and silica-alumina join were made using aluminum nitride-silica-

† HCST 2633 (combined ox ygen $=2.9 \mathrm{wt} \%$ ), H. C. Starck, Goslar, Federal Republic of Germany.

$\ddagger$ Controlled phase $85, \alpha-\mathrm{Si}_{3} \mathrm{~N}_{1}=85 \mathrm{wt} \% ; \beta-\mathrm{Si}_{3} \mathrm{~N}_{1}=12 \mathrm{wt} \% ;$ combined oxygen $=1.8$ wt $\%$, Kawecki-Berylco Industries, Inc., Reading, $\mathrm{Pa}$

$\S$ Linde A or calcined alumina A-16, $>99.5 \mathrm{wt} \% \mathrm{Al}_{2} \mathrm{O}_{3}$; Aluminum Co. of America, Pittsburgh, $\mathrm{Pa}$.

IFlint 25, >99.5 wt\% $\mathrm{SiO}_{2}$; Rovin Ceramics, Dearborn Heights, Mich. 


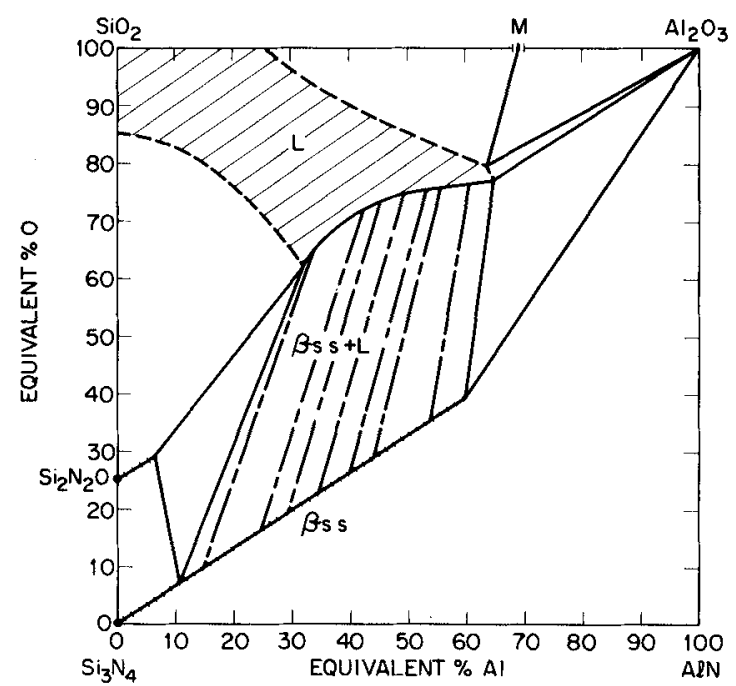

Fig. 1. Part of isothermal section of the system $\mathrm{Si}_{4} \mathrm{~N}_{4}$-AlN$\mathrm{SiO}_{2}-\mathrm{Al}_{2} \mathrm{O}_{3}$ at $1750^{\circ} \mathrm{C}$ showing solid-liquid equilibria; $\beta$-ss $=\beta-\mathrm{Si}_{3} \mathrm{~N}_{4}$-based solid solution, $M=$ mullite $\left(3 \mathrm{Al}_{2} \mathrm{O}_{3}\right.$. $\left.2 \mathrm{SiO}_{2}\right), L=$ liquid.

alumina, silicon nitride-silica-aluminum nitride, and silicon nitride-aluminum nitride-alumina as starting materials. The first group was the most commonly used since aluminum nitridecontaining mixtures equilibrated more readily than silicon nitridecontaining mixtures.

The selected compositions were made by milling the requisite amounts of starting materials in a tungsten carbide jar with tungsten carbide balls and high purity methanol $(<0.2 \%$ water) for 30 to 60 min. It was found that the nitrides ( $\mathrm{AlN}$ and $/$ or $\mathrm{Si}_{3} \mathrm{~N}_{4}$ ) are hydrolyzed, and thus pick up oxygen, if a significant amount of water is present in the grinding medium. Therefore, contact with water must be avoided during milling to preserve the overall composition of the as-weighed mixture. Tungsten carbide impurity introduced during milling was $<1.5 \mathrm{wt} \%$. The milled mixture was dried in shallow glass disks over a laboratory heater and cold-pressed into a pellet $(1.3 \mathrm{~cm}$ in diam. by $1.3 \mathrm{~cm}$ thick) at $110 \mathrm{MPa}$. The pellet was put in a boron nitride crucible and, in most cases, packed in powder of the same composition to minimize weight loss in the pellet during firing.

Firing was done in a nitrogen atmosphere in an induction furnace using a graphite susceptor. A small nitrogen flow was maintained during firing. The heating rate was $350^{\circ} \mathrm{C} / \mathrm{min}$ and various holding times were used at different firing temperatures. Temperature was measured with an optical pyrometer. The specimens were furnacecooled at a rate of $\approx 250^{\circ} \mathrm{C} / \mathrm{min}$ to $1000^{\circ} \mathrm{C}$. Further cooling to room temperature was somewhat slower.

The specimens selected for quantitative measurements were those that showed minimum weight loss when fired and that gave equilibrium phase assemblages. Equilibrium was assumed to have been attained when the number, type, and amounts of phases, as determined by XRD, did not vary with time at a fixed temperature. Equilibrium was also confirmed in some selected specimens by obtaining the same type and amounts of phases from different starting materials for a given composition. Whenever a substantial amount of liquid ( $>$ about 10\%) occurred at the firing temperature, equilibrium was readily achieved, typically within $15 \mathrm{~min}$.

The use of packing powder, rapid heating, and short holding time at the firing temperature kept the weight loss in the pellet at $<1.5 \%$ in most cases. However, compositions containing $>40 \mathrm{eq} \% \mathrm{O}$ and $<40$ eq $\% \mathrm{Al}$ underwent large weight losses ( 5 to $15 \%$ ) when fired at $1750^{\circ} \mathrm{C}$. Excessive weight loss did not occur at $\leq 1650^{\circ} \mathrm{C}$. About 50 compositions, lying in the area above the $\beta$-ss line in Fig. 1, were fired at $1750^{\circ} \mathrm{C}$ to establish the isothermal section representing solid-liquid equilibria. Some selected compositions were fired at $\leq 1650^{\circ} \mathrm{C}$ to determine subsolidus phase equilibria and the tempera- ture and composition of the lowest melting point. The fired specimens were examined mainly by XRD, and in some cases metallography, to determine the number and type of phases present. An automatic recording diffractometer with $\mathrm{Cu} K \alpha$ radiation at $40 \mathrm{kV}$ and $15 \mathrm{~mA}$ was used. The samples were scanned between $10^{\circ}$ and $80^{\circ} 2 \theta$ at a rate of $2^{\circ} / \mathrm{min}$. Firing conditions and phases present in various specimens after firing are given in Table $1 .^{*}$

Standard quantitative $\mathrm{X}$-ray powder diffractometry ${ }^{8}$ was used to determine the amount of $\beta$-ss in the selected specimens in the $\beta$-ss + liquid field to establish the tie lines in this 2-phase field at $1750^{\circ} \mathrm{C}$. The specimens were ground into powder for this purpose. Calibration standards were made using $10 \mathrm{wt} \%$ alumina as an internal standard with different amounts of single-phase $\beta$-ss powder and silicon powder as a filler. Alumina could be used as an internal standard because the specimens in the $\beta-s s+$ liquid field contained no alumina themselves. Initial trials using integrated intensities of the diffraction peaks scanned at $0.2 \%$ min showed that no substantial improvement in the analysis was achieved by using the integrated intensities instead of the peak heights scanned at $2 \%$ min. Therefore, the peak heights in the diffraction patterns scanned at $2 \% \mathrm{~min}$ were taken as a measure of the concentration of a given phase in a powder mixture.

A calibration curve of the peak-height ratio vs wt $\% \beta$-ss was made from the diffractometer traces of the standards. The peakheight ratio here refers to the ratio of the peak height of (301) or (321) reflection of $\beta$-ss to the peak height of $(012)$ or (113) reflection of the internal standard $\alpha-\mathrm{Al}_{2} \mathrm{O}_{3}$. The experimental error in determining the amount of $\beta$-ss by this method is estimated to be \pm 4 $w t \%$. The composition of $\beta$-ss in these selected specimens was determined from the change in the $\beta$-ss lattice parameters. For this purpose, a calibration curve was made ${ }^{9}$ for lattice parameters vs eq\% $\mathrm{Al}$ in different hot-pressed single-phase $\beta$-ss standards. The scanning rate on the diffractometer used for the lattice parameter change measurements was $0.5 \% \mathrm{~min}$. The basis for determining tie lines in the $\beta$-ss + liquid field from the amount and composition of $\beta$-ss in the fired specimens of this field is discussed in the next section.

\section{Resuits and Discussion}

Solid-liquid equilibria at $1750^{\circ} \mathrm{C}$ determined in this study are shown in Fig. 1 in equivalent percent representation. ${ }^{5}$ At this temperature, $x_{1}$ phase is molten; evidence for this is presented later. Tie lines for the $\beta$-ss + liquid field and the corresponding part of the liquidus curve were established from the compositions and amounts of $\beta$-ss in selected specimens which had overall compositions in this 2-phase field. This derivation was possible because, during cooling from $1750^{\circ} \mathrm{C}$, no significant amount of $\beta$-ss crystallized from the liquid phase as shown by the fact that compositions lying just above the liquidus curve (solid line) in the all-liquid field showed only $x_{1}$ as the crystalline phase. No $\beta$-ss was detected in the se specimens by XRD. The minimum concentration of $\beta$-ss that could be detected in synthetic mixtures was $3 \mathrm{wt} \%$, which means that those compositions which are totally liquid at $1750^{\circ} \mathrm{C}$ partially crystallized into $x_{1}$ and the rest remained as a glass and that $<3$ wi $\% \beta$-ss precipitated during cooling.

Another feature indicating that no significant amount of $\beta$-ss crystallized during cooling in the 2-phase $\beta$-ss + liquid field is the fact that two compositions lying on the same tie line but containing significantly different amounts of liquid at $1750^{\circ} \mathrm{C}$ did not give different lengths of the tie line. These composition pairs are identified by the numbers 5,$6 ; 7,16$; and 8,30 (Table I). The part of the liquidus determined from the $\mathrm{X}$-ray results is represented by the solid line in Fig. 1. It matches well with the melting behavior and microstructural observations. A similar determination of tie lines for the $\mathrm{Si}_{2} \mathrm{~N}_{2} \mathrm{O}$-ss + liquid field and the corresponding liquidus could not be done since liquids in this field crystallized $\mathrm{Si}_{2} \mathrm{~N}_{2} \mathrm{O}$-ss on cooling and the specimens in this field showed large weight losses by vaporization when fired at $1750^{\circ} \mathrm{C}$. Therefore, the liquidus here was determined from the melting behavior and microstructural

* For Table I. order ACSD-143 from Data Depository Service, The American Ceramic Society, 65 Ceramic Drive, Columbus, Óhio 43214 
Table II. Lattice Parameter Changes in $\mathrm{Si}_{2} \mathrm{~N}_{2} \mathrm{O}$ Solid Solution

\begin{tabular}{cccccc}
\hline \multicolumn{2}{c}{ Comp. } & & & \\
\cline { 1 - 2 }$(\mathrm{eq} \%)$ & $\mathrm{O}(\mathrm{eq} \%)$ & & $a(\AA)$ & $b(\AA)$ & $c(\AA)$ \\
\hline 0 & 25.5 & & 8.890 & 5.488 & 4.857 \\
2.5 & 26.3 & & 8.895 & 5.507 & 4.857 \\
6.3 & 30.0 & 8.906 & 5.529 & 4.859 \\
\hline
\end{tabular}

The segments of the liquidus for the mullite + liquid and the alumina + liquid fields were deduced from the phases present in the fired specimens as determined by XRD and are also shown as dashed lines. The extent of the liquid field found here is in reasonable agreement with that tentatively proposed by Layden ${ }^{7}$ from DTA and microstructural studies. However, the shape of the liquidus is quite different, particularly for the $\beta$-ss + liquid field. This field is larger than Layden's and its liquidus curves more strongly toward the $\mathrm{N}_{2}$-rich compositions. The solid solubility of $\mathrm{Al}$ in $\mathrm{Si}_{2} \mathrm{~N}_{2} \mathrm{O}$ was determined from lattice parameter changes of the single-phase specimens and the appearance of secondary $x_{1}$ and $\beta$-ss phases in the neighboring compositions. The lattice parameters of $\mathrm{Si}_{2} \mathrm{~N}_{2} \mathrm{O}$-ss are given in Table II.

The composition $\mathrm{Si}_{12} \mathrm{Al}_{18} \mathrm{O}_{3 ! 1} \mathrm{~N}_{8}$ (i.e. $2 \mathrm{~S}_{3} \mathrm{~N}_{4} \cdot 9 \mathrm{Al}_{22} \mathrm{O}_{3} \cdot 6 \mathrm{SiO}_{2}$ ) gave

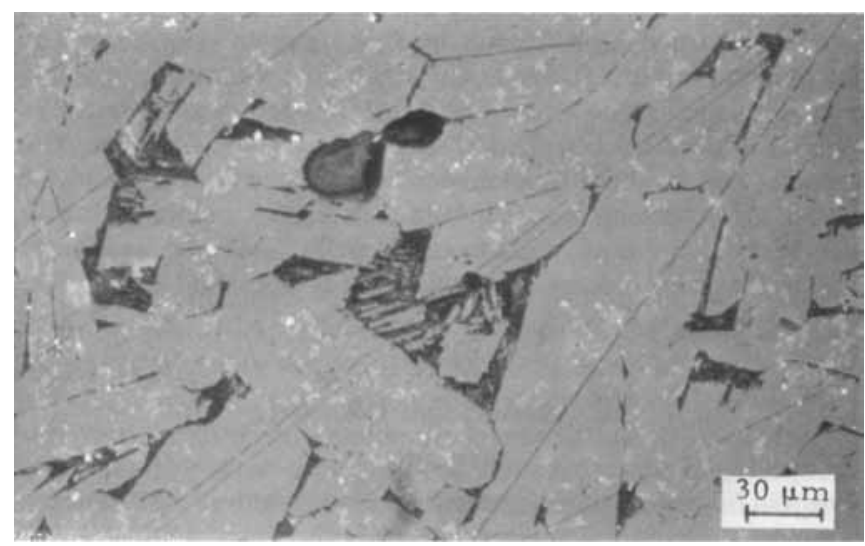

Fig. 2. Optical micrograph of polished section of $53 \mathrm{eq} \% \mathrm{Al}-76 \mathrm{eq} \% \mathrm{O}$ specimen fired at $1750^{\circ} \mathrm{C}$ for $10 \mathrm{~min}$; $\mathrm{HF}$ etched.

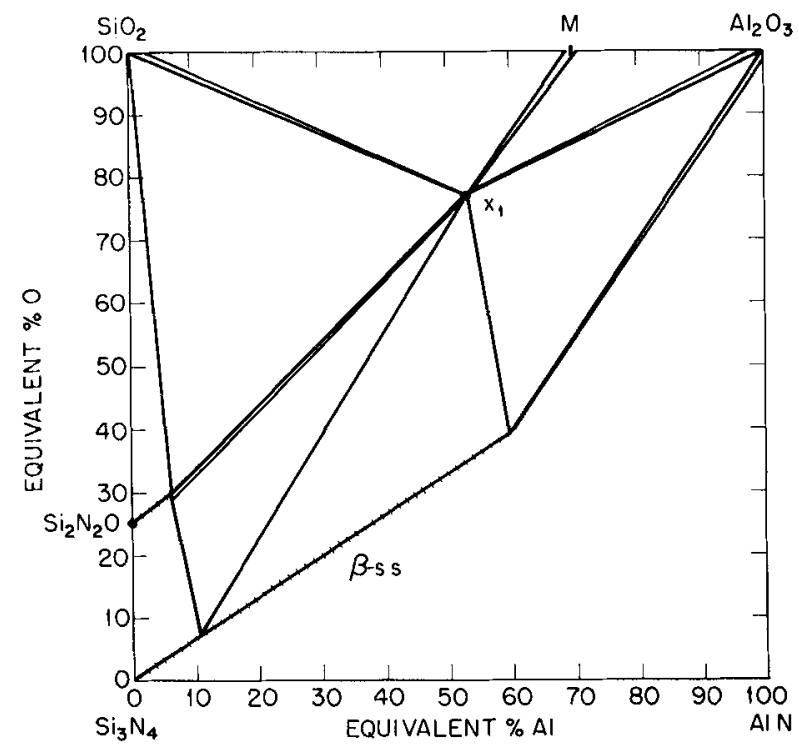

Fig. 3. Subsolidus phase equilibria; $x_{1}=\mathrm{Si}_{12} \mathrm{Al}_{18} \mathrm{O}_{39} \mathrm{~N}_{8}$. the highest peak intensities for the $x_{1}$ diffraction pattern and showed no other crystalline phases after firing at $1750^{\circ} \mathrm{C}$. Microstructural observations showed that this composition contained less glass than any other compositions having $x_{1}$ as the only crystalline phase. Furthermore, when fired at $1650^{\circ} \mathrm{C}$ this composition gave $x_{1}$ phase only, whereas neighboring compositions contained secondary mullite or $\beta$-ss. Therefore, it is suggested that the stoichiometric composition of $x_{1}$ is $\mathrm{Si}_{12} \mathrm{Al}_{18} \mathrm{O}_{39} \mathrm{~N}_{8}$. When heated to $1750^{\circ} \mathrm{C}$, this composition spread freely in the crucible (like a melt). An optical micrograph (Fig. 2) of a polished section of this composition shows large, elongated $x_{1}$ grains, with some glass present along the grain observations alone; it is drawn as a dashed line, indicating a somewhat larger margin of error.

Some of the specimens (Nos. 10, 41, 43, and 44 in Table I) that experienced large weight losses in firing were dissolved in a borate glass made of equal weight proportions of $\mathrm{Na}_{2} \mathrm{~B}_{4} \mathrm{O}_{7}$ and $\mathrm{LiBO}_{2}$. The glass samples were then analyzed for $\mathrm{Si}$ and $\mathrm{Al}$ by the electron microprobe analyzer and for $\mathrm{N}_{2}$ content by wet chemical analysis. ${ }^{10}$ In this analysis, $\mathrm{NH}_{3}$ was liberated from the specimens by dissolving them in lithium hydroxide. The $\mathrm{NH}_{3}$ liberated was determined volumetrically using standard $\mathrm{H}_{2} \mathrm{SO}_{4}$. The analyses showed that $\mathrm{Si}$, $\mathrm{N}_{2}$, and $\mathrm{O}_{2}$ were lost by vaporization but that the $\mathrm{Al}$ content of the specimens increased. As a result, the overall composition shifted toward the AlN corner.
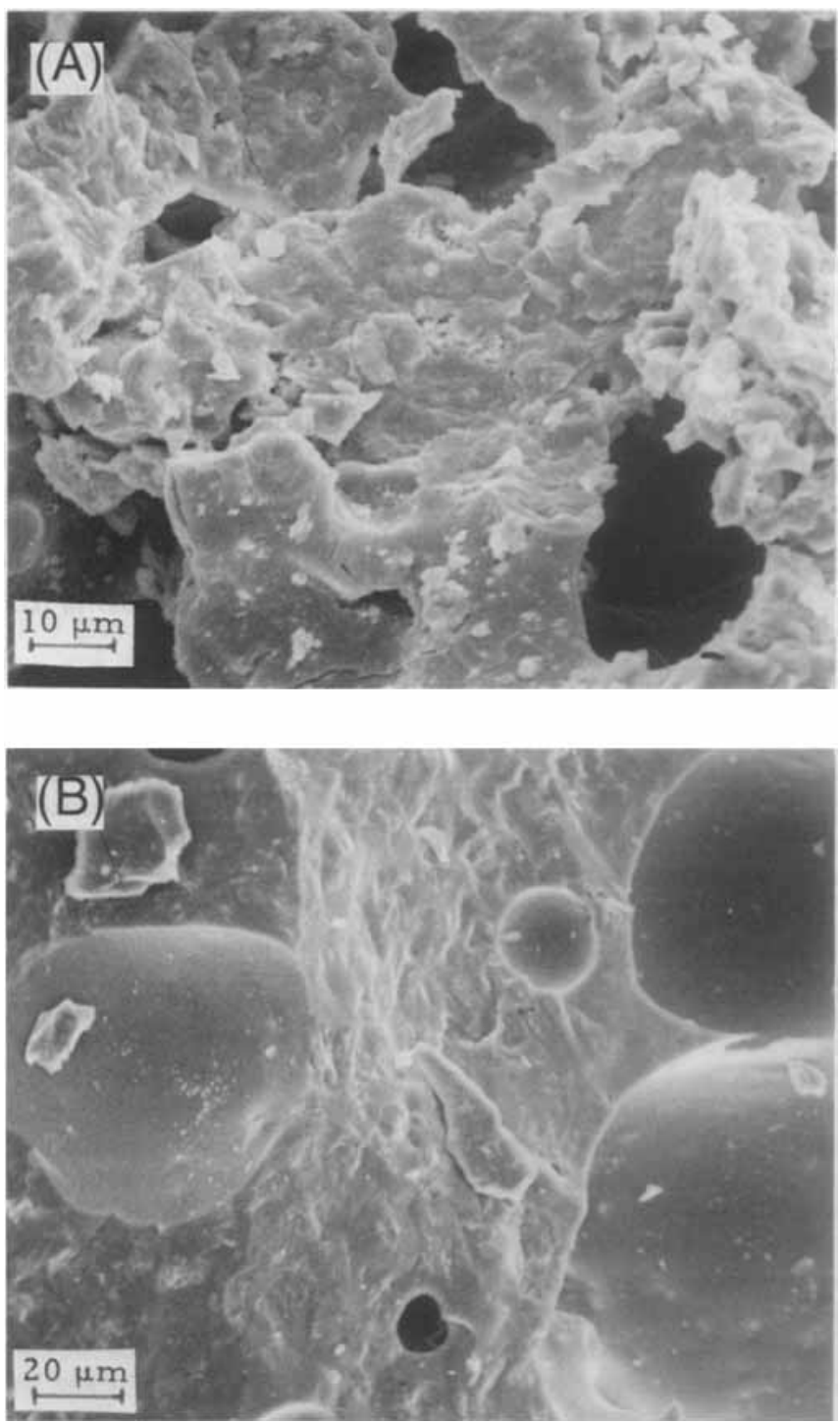

Fig. 4. Scanning electron micrographs of fracture surfaces of 10 eq\% Al-90 eq\% O specimen fired at $(A) 1450^{\circ} \mathrm{C}$ for $2 \mathrm{~h}$ and $(B) 1500^{\circ} \mathrm{C}$ for $2 \mathrm{~h}$. 
boundaries. A few light-colored $\beta$-ss grains (estimated as $<2$ vol\%) which apparently precipitated from the $x_{1}$ phase during cooling are also visible. Thus, if this is the single-phase $x_{1}$ composition, the specimen must be completely molten at $1750^{\circ} \mathrm{C}$ since the specimen fired at this temperature showed no other crystalline phases in the XRD pattern. The melting temperature of the $x_{1}$ phase is estimated as $1720^{\circ} \mathrm{C}$. This composition lies on the line joining $\mathrm{Si}_{3} \mathrm{~N}_{4}$ and mullite $\left(3 \mathrm{Al}_{2} \mathrm{O}_{3} \cdot 2 \mathrm{SiO}_{2}\right)$ compositions.

Subsolidus phase equilibria in part of the system are shown in Fig. 3. The lowest-melting composition is $\approx 10 \mathrm{eq} \% \mathrm{Al}-90 \mathrm{eq} \% \mathrm{O}$ which melts at $1480^{\circ} \mathrm{C}\left( \pm 20^{\circ} \mathrm{C}\right)$. The evidence for melting in this composition is seen in the scanning electron micrographs of the fractured surfaces (Fig. 4). The specimen fired at $1450^{\circ} \mathrm{C}$ shows no rounded pores, whereas the specimen fired at $1500^{\circ} \mathrm{C}$ shows such pores which occur when densification takes place in the presence of a liquid. The appearance of the specimens and the extent of densification also indicated a large amount of liquid in the $1500^{\circ} \mathrm{C}$-fired specimen and little in that fired at $1450^{\circ} \mathrm{C}$.

\section{References}

${ }^{1}$ S. Boskovic, L. J. Gauckler, G. Petzow, and T. Y. Tien, "Reaction Sintering Forming $\beta-\mathrm{Si}_{3} \mathrm{~N}_{4}$ Solid Solutions in the System $\mathrm{Si}, \mathrm{Al} / \mathrm{N}, \mathrm{O}: \mathrm{I}, "$ Powder Metall lnt., 9 [4] $185-89$ (1977).

Appl. Phys., 10 [11] 1637 (1971). .

K. H. Jack and W. J. Wilson, "Ceramics Based on the Si-Al-O-N and Related Systems," Nature (London), Phys. Sci., 238 [80] 28-29 (1972)

${ }^{4}$ Yoichi Oyama, "Solid Solution in the Ternary System $\mathrm{Si}_{3} \mathrm{~N}_{4}-\mathrm{AlN}-\mathrm{Al}_{2} \mathrm{O}_{3}$, , Jpn. J. Appl, Phys, 11 [5] 760-61 (1972)

${ }^{5}$ L. J. Gauckler, H. L. Lukas, and G. Petzow, "Contribution to the Phase

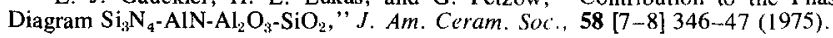

6 P. L. Land, J. M. Wimmer, R. W. Burns, and N. S. Choudhury, "Compounds and Properties of the Si-Al-O-N System," Teeh. Rept. AFML-TR-75-209, Air Force Properties of the Si-Al-O-N System,"' Teeh. Rept. AFML-
Materials Laboratory, Wright-Patterson AFB, Otio, 1976.

7 G. K. Layden, "Process Development for Pressureless Sintering of SiAlON Ceramic Components," Final Tech. Rept. R75-91072-4, United Technologies Research Center, East Hartford, Conn., 1976.

${ }^{8}$ H. P. Klug and L. E. Alexander, X-Ray Diffraction Procedures for Polycrystalline and Amorphous Materials, 2d ed.; pp. 531-62. Wiley-Interscience, New York, 1974.

${ }^{9}$ L. J. Gauckler, "Phase Equilibria Studies in the System $\mathrm{Si}, \mathrm{Al} / \mathrm{N}, \mathrm{O}$ and $\mathrm{Si}, \mathrm{Al}, \mathrm{Be} / \mathrm{N}, \mathrm{O}^{\prime} ; \mathrm{Sc}$. D. Thesis, University of Stuttgart, Stuttgart, Federal Republic of Germany, 1976 .

${ }_{10} \mathrm{G}$. Glaeser; private communication.

\title{
Hot-Pressing of $\mathrm{Si}_{3} \mathrm{~N}_{4}$ with $\mathrm{Y}_{2} \mathrm{O}_{3}$ and $\mathrm{Li}_{2} \mathrm{O}$ as Additives
}

\author{
L. J. BOWEN, T. G. CARRUTHERS, and R. J. BROOK* \\ Department of Ceramics, University of Leeds, Leeds LS2 9JT, England
}

\begin{abstract}
The rates of densification and phase transformation undergone by $\alpha-\mathrm{Si}_{3} \mathrm{~N}_{4}$ during hot-pressing in the presence of $\mathrm{Y}_{2} \mathrm{O}_{3}, \mathrm{Y}_{2} \mathrm{O}_{3^{-}}$ $2 \mathrm{SiO}_{2}$, and $\mathrm{Li}_{2} \mathrm{O}-2 \mathrm{SiO}_{2}$ as additives were studied. Although these systems behave less simply than $\mathrm{MgO}$-doped $\mathrm{Si}_{3} \mathrm{~N}_{4}$, the data can be interpreted during the early stages of hot-pressing as resulting from a solution-diffusion-reprecipitation mechanism, where the diffusion step is rate controlling and where the reprecipitation step invariably results in the formation of the $\beta-\mathrm{Si}_{3} \mathrm{~N}_{4}$ phase.
\end{abstract}

\section{Introduction}

$\mathbf{A}$ TTEMPTS to improve the high-temperature strength retention of hot-pressed silicon nitride ${ }^{1}$ have included the removal of impurities present in the starting materials, especially $\mathrm{Ca}, \mathrm{Na}$, and $\mathrm{K}$, which concentrate in the glassy grain-boundary phase ${ }^{2}$ and lower its softening point, ${ }^{3}$ and the choice of an additive which aids densification and forms a refractory grain-boundary phase. One additive which satisfies this requirement is yttrium oxide. ${ }^{4}$

The role of yttria in aiding densification is not fully understood. $\mathrm{Gazza}^{5}$ reported that, to obtain rapid densification and the strongest material, 5 to $10 \mathrm{wt} \% \mathrm{Y}_{2} \mathrm{O}_{3}$ additive is needed, whereas typical levels are 1 to $3 \mathrm{wt} \%$ for the magnesia additive used in commercially manufactured hot-pressed silicon nitride. Densification measurements made at $1450^{\circ}$ to $1650^{\circ} \mathrm{C}$ showed that the rate of densification was linear up to 0.70 to 0.80 relative density $(\rho)$, which was attributed to particle rearrangement accompanying the reaction between the additive and either the silicon nitride or the silica films present on the surfaces of the nitride crystallites. X-ray diffractometry (XRD) studies on cold compacts prepared at higher temperatures (up to $1750^{\circ} \mathrm{C}$ ) revealed the presence of crystalline second phases, possibly yttrium silicates formed at the hot-pressing temperature.

Presented at the 79th Annual Meeting, The American Ceramic Society, Chicago, Illinois, April 27, 1977 (Basic Science Division, No. 123-B-77). Received July 29, 1977; revised copy received January 11,1978 .

Supported by the United Kingdom Atomic Energy Authority.

*Member, the American Ceramic Society.
Several attempts have been made to determine the structure and composition of these second phases. ${ }^{4-9} \mathrm{Wills}^{6}$ proposed that a densification-enhancing liquid of composition $\mathrm{Si}_{3} \mathrm{~N}_{4} \cdot 3 \mathrm{Y}_{2} \mathrm{O}_{3}$ formed at hot-pressing temperatures up to $1700^{\circ} \mathrm{C}$ and then reacted with more silicon nitride to produce highly refractory $\mathrm{Si}_{3} \mathrm{~N}_{4} \cdot \mathrm{Y}_{2} \mathrm{O}_{3}$, thus imparting improved high-temperature strength and creep properties to the material. Tsuge $e t$ al. ${ }^{7}$ also identified a crystalline phase of composition $\mathrm{Si}_{3} \mathrm{~N}_{4} \cdot \mathrm{Y}_{2} \mathrm{O}_{3}$ in hot-pressings prepared at $>1750^{\circ} \mathrm{C}$ and tentatively postulated the existence of another second phase of composition $\mathrm{Si}_{3} \mathrm{~N}_{4} \cdot 2 \mathrm{Y}_{2} \mathrm{O}_{3}$. Two other yttrium silicon oxynitride compounds (compositions $\mathrm{Si}_{3} \mathrm{~N}_{4} \cdot 9 \mathrm{SiO}_{2} \cdot 10 \mathrm{Y}_{2} \mathrm{O}_{3}$ and $\mathrm{Si}_{3} \mathrm{~N}_{4} \cdot \mathrm{SiO}_{2}$ $\cdot 4 \mathrm{Y}_{2} \mathrm{O}_{3}$ ) have been isolated. ${ }^{8,9}$

In view of the technological importance of hot-pressed yttriadoped silicon nitride for high-temperature engineering applications, it is desirable to understand more fully the mechanisms of densification and of the simultaneous $\alpha-\beta$ phase transformation ${ }^{10}$ in this material. The present work aims to achieve such an understanding by investigating the hot-pressing and transformation behavior of yttria-doped silicon nitride and by comparing this behavior with that of magnesia-doped and lithia-doped silicon nitride.

\section{Experimental Procedure}

\section{(1) Equipment}

Details of the apparatus and procedures used for hot-pressing have been described elsewhere. ${ }^{10}$ For the phase transformation studies, the $\alpha: \beta$ silicon nitride ratios were measured by XRD with $\mathrm{Ni}$-filtered $\mathrm{Cu} K \alpha$ radiation, using a calibration procedure ${ }^{11}$ based on measurements of the ratio of intensities of the $\alpha_{102}$ and $\beta_{210}$ reflections.

\section{(2) Materials Characterization and Additive Preparation}

The silicon nitride powder used throughout the present work was identical to that used in a previous study with $\mathrm{MgO}$ as additive. ${ }^{10,12}$ The powder, ${ }^{*}$ which contained 94 wt $\% \alpha$ phase, was prepared from

*Allen Clarke Research Laboratories, Towcester, Northamptonshire, United Kingdom 